\title{
ユーザの検索要求に基づいた興味関心の定量的評価
}

\section{Quantified Estimation Method of User's Profile based on Search Query}

\author{
堀 幸雄 \\ Yukio HORI \\ 中山 堯 \\ Takashi NAKAYAMA
}

\begin{abstract}
Users' personal information interests is an important for developing more personally adaptive system to search and to collect information increased. Recently, user profiling system has been used in several research system. However, evaluation approach of these systems was lack of empirical investigation using users' explicit desire. In this paper, we show the evaluation method for user profile using users' search queries as explicit desire. After the experiment, we could confirm the effectiveness of the method.
\end{abstract}

\section{1 はじめに}

これまで情報システムはどのようなユーザが利用しても同一のサービスを提供するものであった . 近年， 情報の量は膨大となり, ユーザの求めるサービス, 利用方法は多樣化している .このような背景のなか, ユー ザに適した形でシステムを利用するパーソナライゼーションが注目されつつある . ユーザの情報に対する 興味や要求をモデル化し, 光れに基づいて大量の情報の中からユーザに適した形で情報を提供するといっ た情報フィルタリング技術などがこれにあたる．

パーソナライゼーションには, ユーザモデル , 扱う情報 , 提示手法の 3 つの自由度があり，とくにユー ザの情報に対する興味を的確に表現するユーザモデルが重要となる . 例えばユーザの持つ興味関心を分析 する研究として橘高らの研究 ${ }^{[5]}$ がある .これはユーザが閲覧したページをユーザの興味のあるページと仮 定し, 閲覧したページをもとにユーザの興味をモデル化している .しかしこの研究ではモデル化されたユー ザの興味関心の評価に，モデル化したユーザの興味関心に合うニュース文書を提示し，提示した情報に対す る適合率という指標が用いられる .

ユーザの興味関心とは情報に対する要求であり，データベースシステムに与える query のような明示的 な要求と提示されるまでユーザ自身も気付いていない暗黙的な情報に対する要求の 2 つの側面で考えるこ とができる . 先行研究における情報の提示によるユーザモデルの評価は後者の暗黙的なユーザの興味関心 を評価する手法である .これではユーザモデルを漠然とした情報に対する興味関心を評価したにすぎない． 本研究ではユーザの情報に対する明示的な要求を用いてユーザの興味関心を同定する方法を提案する . ユーザが検索エンジンに投入する検索キーワードはユーザの知りたい興味関心光のものを表していると仮 定し，これを用いてプロファイルを評価する方法を提案する . またユーザの興味関心のモデル化には, 自己 組織化マップを用いて閲覧したページの特徵をマップに投影したものを用いた .

以下, 2 節で先行研究におけるユーザの興味関心のモデル化手法について述べる. 光して 3 節で本研究 で提案する興味関心パターンマップの抽出手法について述べる . 4 節で得られた興味関心をユーザが検索エ ンジンに投入したキーワードで評価する方法を述べ， 5 節で検討すべき課題を述べ，まとめとする．

\section{2 関連研究}

ユーザの Web 閲覧時の挙動などからユーザの興味関心を抽出する手法は多数提案されている ${ }^{[6]}$.KANSHIN [1] や blogWatcher ${ }^{[2]}$ などは blog サイトから RSS $^{1}$ を定期的に収集し, 記事の解析を行い, blog サイト (ユーザ) の興味関心パターンの分析を行なっている . しかしながらこれら研究では blog や BBS などある 特定のサービスを用いたものであり，これでは該当サービス上での興味関心は把握できるものの，サービス 外を含めユーザの大域的な行動を分析していないため，ユーザの興味関心を正しく把握できていないのが 現状である。

またユーザの Web 閲覧時の情報行動からユーザの興味関心に関する情報を取得する研究もある . 橘高ら の研究 ${ }^{[5]}$ ではユーザの閲覧したページ全てを興味のあるページと仮定し，閲覧したページをもとにユーザ

\footnotetext{
†香川大学 情報基盤センター Information Technology Center, Kagawa University horiyuki@itc.kagawa-u.ac.jp

§神奈川大学理学部 Faculty of Science, Kanagawa University, nakayama@info.kanagawa-u.ac.jp

${ }^{1}$ Rich Site Summary: Web サイトの見出しや要約などを記述した XML データ
} 
の興味を単語ベクトルでモデル化している .この場合 Web サーバまたはプロキシサーバのログからユーザ のWeb 閲覧行動の分析を行なう．また閲覧したページ全てに興味があると仮定せずに，明示的な操作 (マ ウス操作 ${ }^{[10]}$, 閲覧中の視線 ${ }^{[11]}$ など) からユーザの興味関心をモデル化する方法もある .

しかしこれら研究ではモデル化されたユーザの興味関心の評価に，モデルを元に推薦した情報がユーザ に適合するか否かという観点で適合率の指標が用いられる．この評価方法はユーザの情報に対する暗黙的 な興味関心を含んだ形で評価される .

ユーザモデリングというように人間を系に含む技術では観測されるデータには多樣の認知的要因が関係 し，不規則なノイズが含まれると考えられる.ユーザプロファイルのさらなる精度向上のためにはユーザの 情報に対する明示的な要求を含んで評価することが必要である. 乥こで本研究では従来のユーザの Web 閲 覧行動などから生成されたユーザモデルをユーザ自身の明示的な情報に対する要求を用いて評価する方法 を提案する.

本研究ではユーザの閲覧行動パターンが網羅的に記録された Web アクセスログからユーザの興味関心パ ターンを抽出し, 自己組織化マップによりマップ上にモデル化する . ユーザの興味関心を 2 次元平面上に 射影することで見た目にもわかりやすく抽出することが可能となる．弚して得られた興味パターンマップ がどの程度ユーザの興味関心を現しているのかを，ユーザが検索エンジンに投入したキーワードを用いて 評価する方法を提案し，キャンパス内ネットワークでの評価実験結果について報告する．

\section{3 興味関心マップの抽出}

ここではユーザから興味関心マップを抽出する手法を述べる . 各ユーザの興味関心マップを抽出するまで の全体の流れを図 1 に示す .

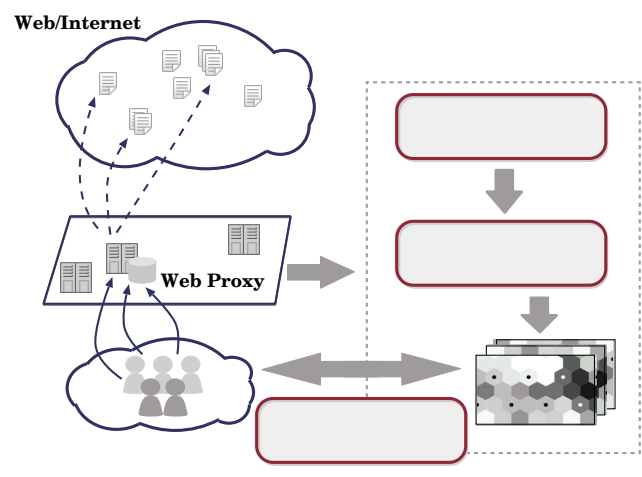

図 1: 興味関心マップ抽出システムの概要

\section{1 ログ解析}

まずユーザの Web 閲覧履歴を HTTP プロキシサーバ2のログから取得する . プロキシサーバはクライア ントから要求のあった URL をもとに Web コンテンツを取得し，クライアントへ転送するものである．プ ロキシサーバのログフォーマットを下記に示す．

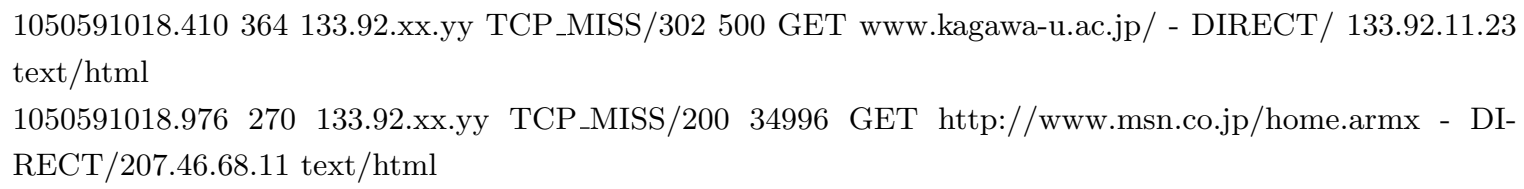

上記のログから閲覧日時, Web ページ (URL) , クライアント IP アドレスを取得する.クライアント IP アドレスから同時刻に谷のマシンを利用したユーザを特定する．ただし個人情報保護の観点から，本研究 では実際のユーザ ID をランダムな ID へと変換している．また本システムで対象とする Web コンテンツ はコンテンツタイプが text/html といった単語抽出可能なもののみとした . ログ解析によりユーザ $u_{i}$ ごと に閲覧した Web ページ $p_{j}$ の集合 $P_{j}=\left\{p_{1}, p_{2}, \ldots, p_{n}\right\}$ を作成する .

次にユーザ $u_{i}$ ごとにページコンテンツの特徵を解析する . まず HTML からタグを取り除き，テキスト

\footnotetext{
${ }^{2}$ http://http://www.squid-cache.org/
} 
に変換処理を行なう．乥してテキスト部分に対し，mecab ${ }^{3}$ を用いて形態素解析を行ない単語に分割する。 本システムでは，一般名詞，及び固有名詞に属する語を対象とする．またストップワード処理として下記の ものを除外した .

1. 名詞の数, 接続, 記号.

2. ひらがな, カタカナ 1 文字の単語 .これらは形態素解析に失敗している可能性が高いために除外した .

3. 全体で出現頻度に閾値 $\tau$ を設定する . $\tau<10 \%$ の低頻度語を除外した．

こうして各ページの特徵ベクトル $p_{j}=\left\{w_{1}, w_{2}, \ldots, w_{m}\right\}$ を得る . 各単語 $w_{i}$ には tf-idf により重み付け を行なった。

$$
\begin{gathered}
w_{i}(t, p)=\operatorname{tf}(t, p) \cdot \operatorname{idf}(t) \\
\operatorname{idf}(t)=\log (N / \operatorname{df}(t))
\end{gathered}
$$

ただし, $\operatorname{tf}(t, p)$ は Web ページ $p$ における単語 $t$ の出現頻度であり， $N$ はユーザの閲覧した総 Web サイ 卜数, $\operatorname{df}(t)$ は単語 $t$ が 1 回以上出現する Web サイト数である.ここで Web サイトとは同一ドメインの ことを意味する．

\section{2 興味関心マップの作成}

まず各単語 $w_{i}$ を Web サイトごとの tf-idf で重み付けされた值 $v_{1} \sim v_{n}$ とし，次式のベクトルで表す．

$$
w_{i}=\left\{v_{1}, v_{2}, \ldots, v_{n}\right\}
$$

$w_{i}$ は多次元べクトルで構成されるためこのままではユーザの興味関心の直接的把握が困難なため, 適切 なクラスタリングを行ない，次元圧縮を行なう必要がある .ここで自己組織化マップ ${ }^{[4]}$ を用いてユーザの 閲覧した Web ページの特徵相互の距離関係を可能な限り保持した状態でこの特徵ベクトルを 2 次元平面上 に写像する。

自己組織化マップは 2 層のニューラルネットワークで構成され，入力層に入力される特徵ベクトルを $w_{i}$, 出力層のノードに連結される参照ベクトルを，

$$
m_{i}=\left\{\mu_{i 1}, \mu_{i 2}, \ldots, \mu_{i n}\right\}
$$

とする .自己組織化マップ生成の手順は次の通りである .

1）参照ベクトル $m_{i}$ を初期化する .

2) 次式により入力 $w_{i}$ に対する最近傍ノード $c$ を決定する.

$$
c=\min \left\|m_{i}-w_{i}\right\|
$$

3）最近傍ノード $c$ と光の近傍ノードを更新する

$$
\begin{gathered}
m_{i}(t+1)=h_{c i}\left(m_{i}(t)-w_{i}(t)\right) \\
h_{c i}=\alpha \exp \left(-\left(\left\|r_{i}-r_{c}\right\|^{2}\right) / 2 \sigma^{2}\right)
\end{gathered}
$$

ここで $\alpha$ は学習係数であり， $h_{c i}$ は近傍関数である $. r_{i}, r_{c}$ は弚れ羿れノード $i, c$ の位置ベクトルを現わす.

以上の手順により 2 次元平面に射影されたユーザの興味関心マップを生成する .こうして得られたユー ザの興味関心マップの例が図 2 である.

図 2 の興味関心マップはあるユーザの 2005 年 9 月 1 日の Web 閲覧行動から得たものであり，特徵べ クトルは約 1600 の単語数，12 の閲覧サイト数から構成される. 乥して興味関心マップは $12 \times 8$ の計 96 の 出カノードとし， 1 つのノードに 2 つの単語までを割当てると設定したため，特徵べクトルの約 $10 \%$ が興 味関心マップに現れていることになる。

このマップには 2005 年に開催された万博愛・地球博に関連するクラスタ (図 3 左)やバスや JR といっ た移動手段に関連するクラスタ (図 3 右) か現れており，このユーザかう博愛・地球博に興味があったこと が推測できる .

実際このユーザはこの興味関心マップを抽出した一日の間 「名古屋 観光」「名古屋駅 アクセス」「万博 $\mathrm{EXPO}$ シャトル」といった検索キーワードを投入しており，弚れに関連した「愛 地球」,「ホテル 愛知」， 「JR きっぷ」などの単語がマップ上に出現している．

\footnotetext{
${ }^{3}$ http://mecab.sourceforge.jp/
} 


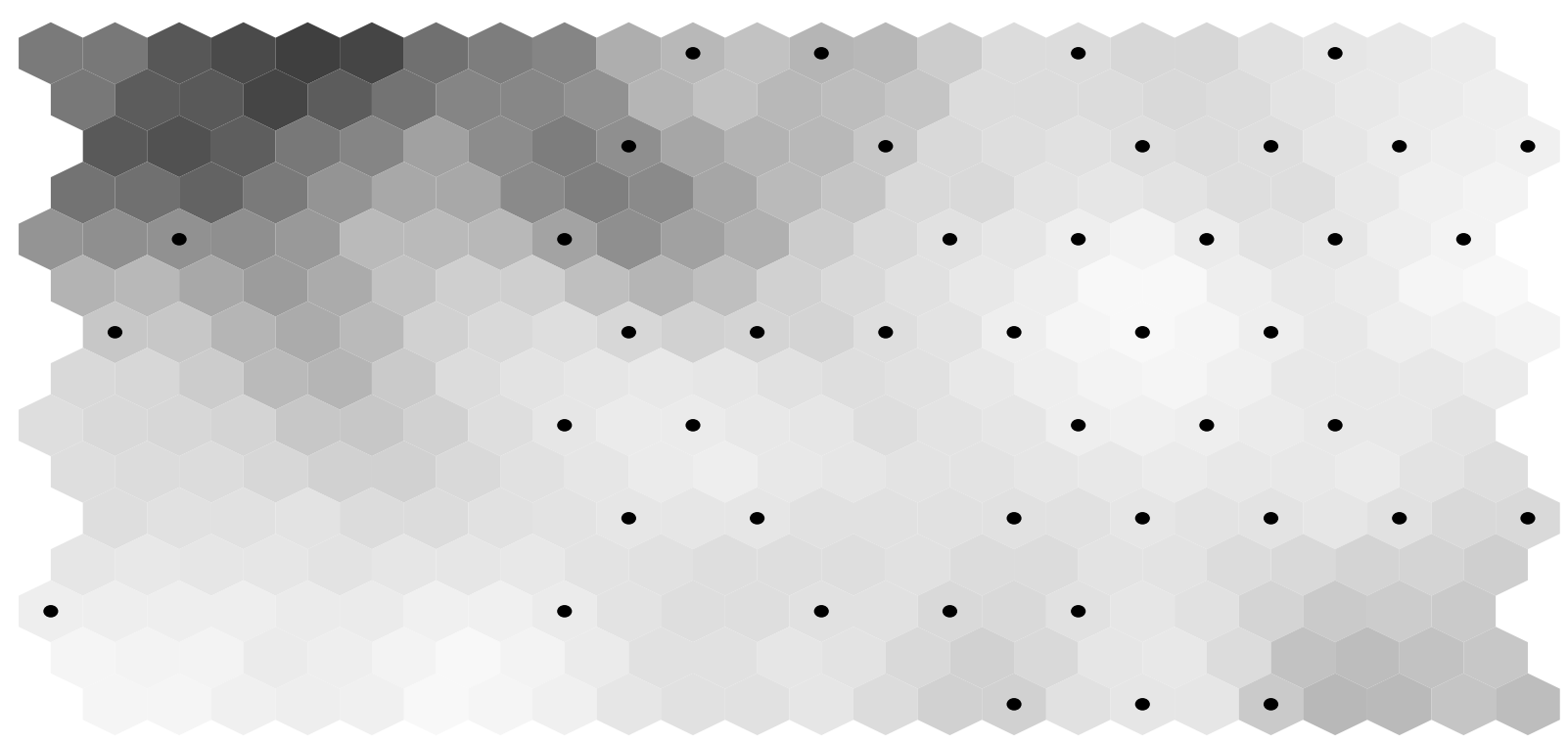

図 2: 得られたユーザの興味関心マップ

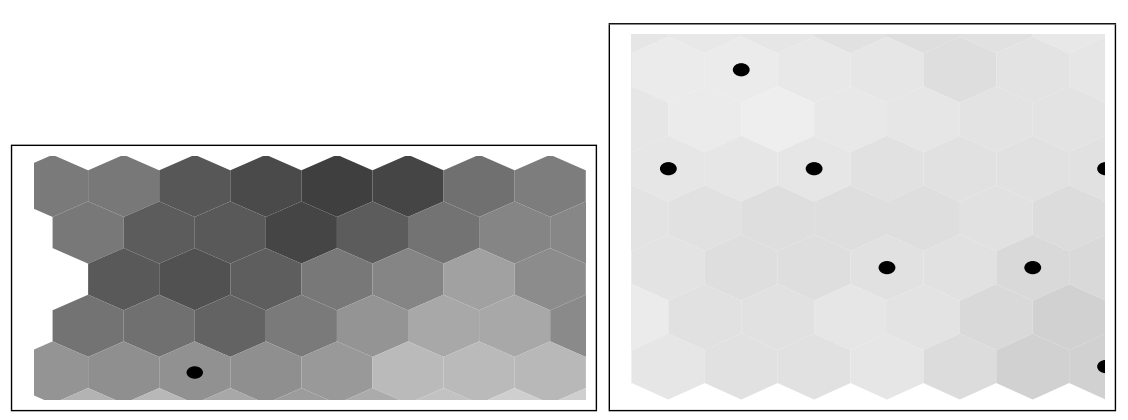

図 3: 興味関心マップ上のクラスタ

\section{4 評価実験}

ここでは得られた興味関心マップがどの程度ユーザの興味を現しているのかを評価する方法とキャンパ スネットワーク内における実験結果について述べる．

\section{1 実験方法}

我々の目的は抽出したユーザプロファイリングがユーザの明示的な要求からどれくらいの精度を持って いるかを明かにすることである . 前節でも述べたように , 生成した興味関心マップは光のときのユーザの Web 閲覧の特徵的な単語がクラスタ化されている.さらにユーザの Web 閲覧行動は検索エンジンへ投入し た検索キーワードを元に行なっているものと考えられるので , この検索キーワードに対応する興味感心マッ プ上の単語との類似度がユーザの明示的な要求を用いた興味関心マップとの評価值になると考えられる.

したがって , 興味感心マップの具体的な評価方法は次の手順で行なう.

1. 興味関心マップ生成時 4 におけるユーザが検索エンジンに投入した検索キーワード $K_{i}$ を保存する

2. 検索キーワード $K_{i}$ を興味関心マップ上に当てはめ, 該当するノードに割当てられた単語を $W_{k}$ と する .

3. シソーラス ${ }^{[9]}$ を用いて $K_{i}$ と $W_{k}$ の類似度 $S$ を求める.

ただし検索キーワード $K_{i}$ に対応する興味関心マップ上のノードに単語か割当てられていない場合もある ため, 類似度に加えて再現率 $R$ も評価値とする .

$$
R=\frac{\text { 検索キーワードに対応する単語が存在した数 }}{\text { 検索キーワード総数 }}
$$

4興味関心マップの生成周期は一日とした 
1. のユーザが検索エンジンに投入した検索キーワードの抽出は Web プロキシのアクセスログにおける Web 閲覧ログから抽出する . 具体的には図 4 の形式の URL て現わされるものから検索キーワードのみを 抽出し $K_{i}$ とした .

\author{
http://www.google.co.jp/search?hl=ja\&q=\%E9\%A6\%99\%E5\%B7\%9D \\ \# Google に香川と入れた場合
}

図 4: 検索キーワードを投入した URL 例

検索エンジンの検索キーワードの表現にはアクセスログ解析ツール analog ${ }^{5}$ の表現を用いて Google, Yahoo!, MSN など代表的な検索エンジン 24 システムへ投入した検索キーワードを抽出した .

次に検索キーワードを興味関心マップにあてはめ, シソーラスを用いて該当ノードの単語との類似度を 計算する方法について述べる . シソーラスを用いた単語 (概念) 間の類似度計算方法には一般的にカテゴリ 間の距離を用いる方法 , 共通のカテゴリ数や根からの距離を用いる方法などがある ${ }^{[8]}$.

ここでは類似性判別能力が高いシソーラスにカテゴリ属性をベクトル化して表現し，2 つの単語の類似度 をベクトル間の内積によって計算する方法を用いる ${ }^{[7]}$. ベクトル化による類似度計算方法は次の手順で行 なう。

1. シソーラスをカテゴリでベクトル化する.

2. 均等深度法 ${ }^{[12]}$ によりベクトル次元数の圧縮を行なう．

3. 情報量の比により各カテゴリに重み付けを行なう (次式) .

$$
W_{b}=W_{a} \times \frac{\log \left(\left(\mathrm{C}_{b}+1\right) / \mathrm{N}_{c}\right)}{\log \left(1 / \mathrm{N}_{c}\right)}
$$

ただし,$W_{b}$ はノード $b$ の重み,$W_{a}$ は初期重み, $\mathrm{N}_{c}$ はカテゴリ総数， $\mathrm{C}_{b}$ はノード $b$ の下位カテ ゴリ総数である .

4. 検索キーワードと興味関心マップ上の対応する単語をシソーラスのベクトルで表し $, \overrightarrow{K_{i}}, \overrightarrow{W_{k}}$ とし 次式により類似度 $S$ を計算する.類似度 $S$ は $0 \sim 1$ の間て現される.

$$
S=\frac{\overrightarrow{K_{i}} \cdot \overrightarrow{W_{k}}}{\left|\overrightarrow{K_{i}}\right|\left|\overrightarrow{W_{k}}\right|}
$$

具体的に図 2 のユーザの興味関心マップ生成日に該当ユーザの検索キーワードと光れに対応する興味関 心マップ上の単語を表 1 に示す.

\begin{tabular}{l|l}
\multicolumn{2}{c}{ 表 1: 検索キーワードとマップ上の対応する単語 } \\
\hline \hline 検索キーワード $K_{i}$ & 対応するマップ上の単語 $W_{k}$ \\
\hline 名古屋駅 & 名古屋 \\
観光 & ビジネス \\
アクセス & 周辺 \\
万博 & 愛 ホテル \\
\hline
\end{tabular}

また検索キーワードにマップ上の対応する単語が複数ある場合は最も高い類似度 $S$ のものを採用するこ ととした .

\title{
4.2 実験結果
}

表 2 の期間 , キャンパスネットワーク内のユーザから興味関心マップを生成し, 評価実験を行なった . 光 して兴の評価結果が表 3 である. 評価值は全ユーザの平均である .

ユーザプロファイルの評価結果の比較として Foltz らはプロファイルをアンケートによる明示的な評価を 行なっているが類似度は 0.67 であり ${ }^{[13]}$ ，本稿の自己組織化マップによる閲覧行動のクラスタ化はまずま ずの結果となっていると言える．また彼らの結果では再現率は 0.25 になっているが, 本稿の手法は閲覧行 動が検索キーワードを元に行なわれているために彼らの結果に比べて高い值になっていると思われる .

\footnotetext{
${ }^{5}$ http://www.analog.cx/
} 
表 2: 実験期間，ユーザ数

\begin{aligned} & 実験期間: 2005 年 $8 \sim 9$ 月 \\ & 興味関心マップ抽出タイミング: 1 日単位 \\ & 総ユニザ数: 2,719 人 \\ & ユーザ当たりの平均閲覧数 $(\mathrm{PV}): 314 \\ &$\hline\end{aligned}

表 3: 評価実験結果

\begin{tabular}{rll}
\hline \hline 総検索キーワード数: & 102,034 \\
ユーザ当たりの平均検索キーワード数: & 11.02 \\
類似度 $S:$ & 0.77 \\
再現率 $R:$ & 0.81 \\
\hline
\end{tabular}

\section{5 おわりに}

本稿ではアクセスログをもとにユーザの大域的な Web 閲覧行動から自己組織化マップを用いて興味関心 マップを抽出した . 光の結果見た目にも分かりやすく, ユーザの興味関心とも近い興味パターンマップが取 り出せることを示した . 光してこの興味興味マップの評価にユーザが検索エンジンに投入したキーワード を用いて評価する方法を提案し，実験を行なった．

今後ユーザプロファイルのさらなる精度向上のためにユーザの持つ興味関心の変化や興味関心を長期的 興味と短期的興味に対応させるなどの工夫などが必要である .これはユーザプロファイルの特徵に活性度 という概念を設け，活性度は閲覧したページにより刺激を受け，時間の経過と共に減衰する手法 ${ }^{[15]}$ や長期 の興味関心と一日限りの興味関心を分けてプロファイルを作成する手法 ${ }^{[14]}$ などを適用していくことで対応 できると考えられる．また抽出したユーザの興味関心パターンの遷移や他者との違いの表現方法をどのよ うにするのかといった問題が残されている．また本稿では一日単位でユーザの興味関心マップを生成したが 本稿の興味関心マップは 1 ユーザあたり生成に 30 分弱の時間を要しておりユーザプロファイルを他のシス テムと連携した応用を考える際にはユーザプロファイル構築に要する時間も問題である .

\section{参考文献}

[1] 福原知宏; 村山敏泰; 中川裕志; 西田豊明: ウェブログ記事を用いた関心解析システム, 人工知能学会 第 19 回全国 大会, 2C2-04, 2005.

[2] Nanno, T., Suzuki, Y., Fujiki, T., and Okumura, M.: Automatic collection and monitoring of Japanese Weblogs., WWW 2004 Workshop on the Weblogging Ecosystem, 2004.

[3] 谷口 智哉; 松尾 豊; 石塚 満:Blog コミュニティの抽出と分析, 人工知能学会, 第 6 回セマンティックウェブとオ ントロジー研究会, SIG-SWO-A401-08, 2004.

[4] Kohonen, T.: Self-Organizing Maps, 3rd Edition,Springer-Verlag, 2001.

[5] 橘高博行; 佐藤直之; 鈴木英明; 曽根岡昭直: パーソナライズ情報提供方式の提案と評価，情報処理学会論文誌， Vol.40,No.1,pp.175-187, 1999.

[6] 土方嘉徳: 情報推薦・情報フィルタリングのためのユーザプロファイリング技術 , 人工知能学会誌, Vol.19, No.3, pp.365-372, 2004.

[7] 川島 貴広; 石川 勉: 言葉の意味の類似性判別能力に関するシソーラスと概念ベースの性能比較, 人工知能学会全国 大会 $2 \mathrm{D} 2-10,2004$.

[8] 川島 貴広; 石川 勉: 言葉の意味に関する類似性判別能力における概念ベースとシソーラスとの性能比較 , 情報処 理学会 第 65 回全国大会, 2M-1, pp. 135-136, 2004.

[9] 池原 悟 , 他: 日本語語彙体系, 岩波書店, 1997.

[10] 土方 嘉徳; 青木 義則; 古井 陽之助; 中島 周: マウス挙動に基づくテキスト部分抽出方式と抽出キーワードの有効 性に関する検証, 情報処理学会論文誌, Vol.43, No.2, pp. 566-576, 2002.

[11] 大野 健彦: IMPACT: 視線情報の再利用に基づくブラウジング支援法 ,in Proc. of the 8th Workshop on Interactive Systems and Software (WISS'2000), pp.137-146, 2000.

[12] 平川秀樹; 木村和広:概念体系を用いた概念抽象化手法と語義判定における关の有効性の評価，情報処理学会論文 誌, Vol.44, No.2, pp.421-432, 2003.

[13] Foltz, P.W.,Dumais, S.T.: Personalized information Delivery: An Analysis on Information Filterin Methods, Comm. of the ACM, Vol. 35,, No. 12, pp.51-60, 1992.

[14] 杉山一成; 波多野賢治; 吉川正俊; 植村俊亮: ユーザからの負担なく構築したプロファイルに基づく適応的 Web 情 報検索, 電子情報通信学会論文誌, Vol.J87-D1 No.11, 2004.

[15] 宮原一弘; 岡本敏雄: Web ブラウジングに基づいた興味の定量的同定法と光の協調フィルタリングへの適用，信学 技法, ET97-115, pp.17-24, 1998. 